\title{
Nuevas construcciones y desmantelamientos de la memoria en tres documentales de cine autobiográfico argentino
}

\section{New constructions and forms to dismantle memory in three documentaries of autobiographical Argentinean cinema}

\author{
María Laura Lattanzi \\ Universidad de Buenos Aires \\ mlauralattanzi@gmail.com
}

Resumen - En el presente trabajo nos proponemos explorar los procesos de construcción de memoria transgeneracional y familiar actuales, a partir del análisis de objetos artísticos determinados: tres documentales argentinos de los últimos diez años, de corte autobiográfico, dirigidos por hijos de detenidos desaparecidos. El actual despliegue del fenómeno autobiográfico implica —en las obras que nos interesan- nuevas formas de pensar el testimonio (propio y de los sobrevivientes), involucrando también lo cotidiano y lo familiar como lugares privilegiados en la reconstrucción y reconfiguración de identidades desgarradas. En esta línea afloran múltiples referencias a espacios íntimos, en lo que podríamos llamar una búsqueda de anclajes —espacios, imágenes, objetos, memorias-, pero hay también un énfasis en procesos de construcción y desmontaje de subjetividades, muchas veces marcados por la violencia y el desgarramiento.

Palabras clave: memoria familiar, memoria transgeneracional, testimonio, representación, documentales autobiográficos.

Abstract - This article aims to explore how the familiar and trans-generational memory have been constructed from the analysis of selected art objects: three Argentinean autobiographical documentaries from the past ten years, directed by children of the desaparecidos. The current development of the autobiographical phenomenon involves - in the works of our interest - new ways of thinking testimony (their own and the survivors'), which considers daily routines and familiar intimacy as privileged places in the reconstruction and reconfiguration of broken identities. Thus, multiple references to everyday places, and to familiar aspects emerge in the search of foothold - spaces, images, objects, and memories. However, there is also an accent in the process of constructing and dismantling subjectivities marked by violence and fissure most of the times.

Keywords: Family memory, trans-generational memory, testimony, representation, autobiographical documentaries. 


\section{LA IRREPRESENTABILIDAD Y LA ÉTICA DEL TESTIMONIO}

Dentro del corpus teórico estético-político que surge a partir de la segunda mitad del siglo XX, se ha hecho hincapié en los procesos de elaboración de la memoria traumática que significó la vivencia de determinadas experiencias de horror. De esa forma, se han configurado nuevas preguntas acerca de la posibilidad de narrar y representar semejantes experiencias límite. En muchos casos el análisis se ha centrado en las posibilidades del testimonio y los relatos de vida, cuya narración o representación resulta si no imposible, por lo menos desgarrada, fragmentada. La crisis de la experiencia moderna surge - desde esa perspectiva- de la imposibilidad de narrarla.

Esta idea ha permeado profundamente los estudios sobre la memoria y la representación de la violencia en los últimos años, articulando, de forma a veces no demasiado razonada, la condición de una experiencia extrema y la imposibilidad desde el orden simbólico de dar cuenta de lo real. Y es que en algunos casos el boom de énfasis en lo irrepresentable ha resultado en un uso excesivo del término, que limita su capacidad analítica. Sobre ello advierte Rancière cuando menciona que:

[Hay un uso] inflacionista de la noción de irrepresentable y de toda una serie de nociones a las cuales ésta se conecta fácilmente: lo impresentable, lo impensable, lo intratable, lo irredimible, etcétera. En efecto, este uso inflacionista hace caer bajo el mismo concepto y rodea de un mismo aura de terror sagrado toda clase de fenómenos, de procesos y de nociones que van desde el interdicto mosaico de la representación hasta la Shoah, pasando por lo sublime kantiano, la primitiva escena freudiana, el Grand Verre de Duchamp o el Carré blanc sur fond blanc de Malevith (cit. en Didi-Huberman, 229).

Ahora bien, es ese mismo «uso inflacionista» el que permitió que tales discursos excedieran los ámbitos intelectuales y se desplazaran e instalaran en otros espacios. Y es claramente en el arte - como potencial experimentador de los límites del lenguaje, de la representación, y como constructor de metáforas y alegorías- donde surge el campo más fecundo para ese tipo de reflexiones. Desde aquí abogamos por una concepción del hecho artístico como una producción que se produce siempre a partir de lo imposible, de lo no dado, de alguna clase de silencio, alineándonos con la teoría estética adorniana, para la cual la experiencia estética es un acontecimiento negativo, porque es una experiencia de la negación (fracaso, subversión) de la comprensión, que, sin embargo, está obligada a intentar.

A su vez, es sintomático de la época que muchas de esas discusiones se hayan instalado, profundizado y encauzado a partir del fenómeno cinematográfico. Es en dicho género artístico donde se instalan, problematizan y configuran varios de los discursos en torno a los procesos de elaboración de la memoria, lo irrepresentable y las posibilidades del testimonio como narración.

En el discutido plano de Kapo, de Pontecorvo (1959), se recurre a un travelling de aproximación para reencuadrar en contrapicada el cadáver del personaje que se arroja a la alambra eléctrica. A partir de la exhibición de semejantes imágenes del horror, la discusión giró en torno a la sugerencia de mostrar la muerte como un objeto de deseo, problematizando los límites de lo representable y de la ética de la enunciación —en este caso audiovisual- Para algunos, el límite ético de lo representable y lo presentable se había desplazado irreversiblemente, produciendo así una escalada de filmes que intenta- 
ron estirarlo y llevarlo al extremo, probando que sí era posible «mostrarlo todo». Entre los casos más notorios se encuentra Saló o los 120 días de Sodoma (1975), de Pier Paolo Pasolini. Pero otros criticaron con dureza el travelling de Pontecorvo (o la escena de tortura de Roma Città Apperta de Rossellini, 1945) y se negaron a ver - y reconocerdichas imágenes. Desde esa perspectiva, el límite ético no debía excederse, línea en que se instala Shoah, de Claude Lanzmann (1985). Ahí, el director no recurre a ningún archivo, a ninguna imagen real o reconstruida de los campos o de la época, a ningún cadáver: su filme está compuesto únicamente por testimonios. En efecto, a partir de esa obra los discursos giraron en torno al núcleo de lo indecible y la obscenidad de comprender históricamente, instaurando la idea de que la memoria y la representación — del Holocausto en ese caso- sería una ausencia, pero fundamentalmente del testigo. Posteriormente, la seguidilla de películas que circularon por vías más comerciales, como La Lista de Schindler de Steven Spielberg (1993) o La vida es Bella de Roberto Benigni (1997), dispusieron una discusión en torno a la fetichización y espectacularización del horror.

Pareciera entonces que, a partir de los discursos que esos filmes generaron y que se articularon e incorporaron a toda una literatura relacionada con el tema, tanto desde el ámbito académico como desde otros géneros artísticos, la figura del testigo sobreviviente se ha consolidado como una posición privilegiada para enunciar y dar cuenta de las experiencias traumáticas. Sin embargo, sabemos que fue un proceso de años, durante el cual determinados acontecimientos de la historia —en este caso el Holocausto- lograron instaurar la memoria como un imperativo moral, donde el testimonio asume el papel protagónico. Se consolida así la ética del testigo, en una época que podríamos denominar la era del testimonio.

\section{RELATO DEL HORROR: RECEPCIÓN Y TRANSMISIÓN}

Desde el lugar de los sobrevivientes, el relato personal de lo vivido permite reconfigurar un yo que ha sido quebrado por la lógica concentracionaria, a partir de nominarse y reconocerse en el discurso, pero a su vez, para que se produzca este discurso es necesario - siguiendo las teorías benvenistianas- que haya un receptor, un alocutario dispuesto a escucharlo y a otorgarle - o por lo menos a intentarlo- un sentido a ese relato. Entonces, creemos que es también fundamental destacar la idea de recepción y transmisión.

Si indagamos un poco en la idea de recepción sobre los testimonios de sobrevivientes a experiencias límite, observamos cómo se ha destacado desde la sociedad civil la importancia de relatar esos discursos para que semejantes hechos de horror no vuelvan a suceder, cayendo en la falsa idea de que su continua repetición, su continua rememoración, evita que reaparezcan. Repetir para que no se repita; he ahí la paradoja de la que se desprende el eslogan recordar para no repetir, el cual muchas veces se ha centrado en las figuras del horror y no en los mecanismos que lo hicieron posible, a la vez que omite las preguntas ¿cómo recordamos?, ¿qué recordamos? y, retomando la cuestión de lo indecible, de lo irrepresentable, ¿cómo semejante relato puede ser producido y transmitido?

A su vez, somos conscientes de que muchas veces dicha transmisión se ve mediatizada por los mecanismos de fetichización y espectacularización; lógicas que a su vez responden al núcleo de la tragedia de la cultura moderna y su consecuente crisis de la experiencia. 
Simmel ya nos advertía, a fines del siglo XIX, que en las ciudades modernas el individuo sufría una «hipertrofia» de la conciencia, producto de la incapacidad de absorber y dar cuenta del torbellino de estímulos e impresiones constantes que la ciudad le ofrecía. Es decir, la tragedia de la cultura moderna se produce por una cultura subjetiva que no logra adaptarse al continuo y veloz ritmo de acrecentamiento de producción de objetos de la cultura objetiva. Y es que si algo distingue a la modernidad, dentro de las múltiples definiciones que se han ensayado sobre el concepto, son las condiciones de cambio y fugacidad que ella implica. Desde ese punto de vista, la crisis de la experiencia es también una crisis de la continuidad, condición que bien nos advertía Walter Benjamin en sus Tesis sobre el concepto de Historia.

Por lo tanto, debemos preguntarnos por esa posibilidad de recepción y transmisión cuando la continuidad es más bien un mito moderno que fácilmente se devela como artificio. Porque memoria no es recordar lo que sucedió en el tiempo, sino el procedimiento en el cual el recuerdo, pero también el olvido, juega un rol fundamental. En la formulación de Freud, el olvido es un proceso activo de represión que tiene por objeto proteger al individuo de la ansiedad, el miedo, los celos y demás emociones difíciles. Ahora bien, este concepto de memoria protectora nos es útil para pensar cómo una cultura recuerda. Es decir, si tenemos en cuenta que la memoria cultural contemporánea, compartida y creada por y para una sociedad, es producida gracias al mecanismo de la representación, debemos dar cuenta no sólo de lo que incluye, sino también de lo que excluye, lo que olvida. Nos referimos a la hegemonía actual de las imágenes, ya sean fotográficas, cinematográficas o televisivas, que aspiran a presentarnos signos y discursos de reconocimiento claro y con sentido pleno. A la vez, su poder hegemónico hace visibles algunos aspectos y omite otros, y no solamente gracias a los contenidos que descarta, sino también por la forma narrativa que estructura todo su relato. Claro que ello es inevitable, porque las mismas experiencias originales de la memoria son irrecuperables y porque toda imagen, todo punto de vista, supone un recorte; más allá de que muchas veces este recorte sea conscientemente deliberado para crear determinados efectos en la sociedad. De esa forma, toda lectura de un pasado supone una lectura en perspectiva, ¿o acaso es posible contar o mostrar lo que realmente pasó?

Resumiendo, la transmisión actual de memoria se ve limitada y configurada por esas coyunturas: la imposibilidad de representar ciertos hechos y el uso inflacionario de lo irrepresentable, el boom de la memoria y el testimonio, pero también la industria cultural con sus derivaciones en la hegemonía actual de las imágenes, que aspiran a una representación clara y sin fisuras, y la espectacularización del horror.

Llegado este punto nos preguntamos por las posibilidades de construcción de memoria en las nuevas generaciones: cómo los hijos de la industria cultural, de la ética de lo irrepresentable por un lado y del testimonio por el otro, logran articular un relato de su propia biografía.

\section{HIJOS DE LA MEMORIA}

En la década de los ochenta, Spielgelman, hijo de judíos que sobrevivieron a Auschwitz, nacido en Suecia y exiliado en Estados Unidos, comienza a publicar en entregas su his- 
torieta Maus. En ese caso, el artista recurre a un género no canónico dentro del campo del arte para relatar lo que significa ser hijo de un sobreviviente. El relato da cuenta del horror vivido por su padre, pero desde una mirada crítica y de distanciamiento sobre lo sucedido, que se observa en la elección de narrar desde una figuración animal (los personajes son ratones), pero que también se hace cargo de su lugar como sujeto hijo. Desde aquí Spielgelman articula el recuerdo de su padre, la obligación de representar Auschwitz y la presión de la industria cultural en un relato posmemoria que traspasa los discursos en torno a Lanzmann (como paradigma de la ética responsable del testimonio) y Spielberg (como paradigma de la espectacularización del horror) y se posiciona en una mirada reflexiva en los lindes de la ficción y lo biográfico.

En Latinoamérica observamos la proliferación de ese tipo de relatos, sobre todo a partir del género documental. En el caso argentino podemos mencionar Papá Iván (María Inés Roqué, 2000), Los Rubios (Albertina Carri, 2003) y M (Nicolás Prividera, 2007); mientras que en Chile, Reynalda del Carmen, mi Mamá y Yo (Lorena Giachino Torrens, 2007) y El Edificio de los Chilenos (Macarena Aguiló, 2010). En ellos son las nuevas $\mathrm{y}$ actuales generaciones las que se interrogan por los procesos de memoria subjetiva a partir de ser hijos de padres desaparecidos, si no físicamente, por lo menos con lagunas o «desapariciones» de memoria.

En el caso argentino, como en el de otras dictaduras latinoamericanas, el mecanismo de la desaparición de personas - y de muchos de sus niños que aún siguen siendo buscados- implica para sus hijos y para toda la sociedad actual un proceso de duelo irresuelto. Porque, ¿cómo elaborar el desplazamiento de un objeto perdido, cuando la distancia que tenemos con él aún no está resuelta, cuando el cuerpo es aún un ausente? La ausencia siniestra de los cuerpos imposibilita los rituales ceremoniales sobre los que se apoya el trabajo del duelo e impide la clausura simbólica y catártica. Esta condición, por tanto, significa una profunda aflicción, que deber ser resuelta a través de otras lógicas. Podemos pensar que las más indicadas serían las de las políticas institucionales de los nuevos gobiernos democráticos. Sin embargo, en la Argentina la promesa de justicia y verdad que dieron los Juicios a la Junta Militar fue corta y las condenas a los culpables removidas con la Ley de Obediencia de Vida y Punto Final. Así, la posibilidad de hacer justicia se vio rápidamente clausurada y los militares culpables se retiraron de la escena impunes, dejando los fantasmas con los que la sociedad debía cargar.

\section{LA NUEVA GENERACIÓN SE INCORPORA A LA ESCENA: DOCUMENTALES AUTOBIOGRÁFICOS ARGENTINOS}

En la Argentina comienza a producirse durante la década de los noventa una proliferación de documentales que dan cuenta de distintos hechos sucedidos durante el régimen militar, desde un canon verista. En muchos casos los hijos de las víctimas, ahora adultos, hacen oír su voz y exhiben su mirada sobre la dictadura brindando testimonios, como es el caso de Botín de Guerra, de David Blaustein, 2000. De esa forma, de a poco se irá incorporando a la escena la nueva generación: la de hijos de detenidos desaparecidos y de niños apropiados recuperados. Ahora bien, durante el período se privilegia una urgencia por «dar a conocer» lo que sucedió — propia de una primera etapa de elaboración de la 
memoria-, recurriendo al testimonio como lo verídico y transmitiendo una imagen de los desaparecidos como héroes idealizados, sin profundizar demasiado en el contexto que hizo posible su desaparición ni en los mecanismos de relato que una memoria desgarrada implica.

Pero a partir de la década del dos mil comienzan a surgir documentales que en muchos casos lindan con el género de la ficción e incorporan nuevas formas de pensar la dictadura. Los hijos de detenidos desaparecidos se interrogan acerca de su lugar, desde un lenguaje que se aleja de lo verídico y quiere dar cuenta de sus mecanismos de construcción. En el presente trabajo nos proponemos estudiar tres casos argentinos: Los Rubios, M y Papá Iván.

\section{LOS RUBIOS}

Los Rubios (2003) de Albertina Carri, directora e hija de desaparecidos, parte de la premisa de que es imposible acceder a la reconstrucción del pasado y la verdad sobre sus padres en términos de continuidad y veracidad. Por ello desafía todos los cánones de los documentales tradicionales, que se presentan como verídicos, y desnuda - para hacer visibles- los mecanismos de construcción de un filme y los de construcción de la memoria.

En el primer caso (el de los mecanismos de construcción fílmica), podemos observar las referencias de Carri dentro de la historia del cine. La directora se alinea dentro de la escuela modernista cinematográfica, donde se intensifica la crisis de representación ${ }^{1}$ y se reflexiona sobre sus mecanismos dentro del cine. Ello se observa, por ejemplo, al inicio de la cinta, cuando un personaje se presenta como la actriz que encarnará a la directora en su relato. De esta forma, y a lo largo de toda la obra, la directora - y protagonista de la historia- se desdobla, siendo a veces encarnada por ella misma y otras veces por la actriz. Incluso en muchas escenas puede verse cómo dirige a la actriz que la encarna en la ficción. En cuanto a lo segundo (exhibir los mecanismos de la memoria), Carri hace hincapié en las trabas e imposibilidades que encuentra para contar su propia historia y por lo tanto la del filme: desde la lectura en cámara de la carta del Instituto Nacional de Cine Argentino (INCA) que rechaza financiar su película, hasta los testimonios que parecen no decir nada importante respecto a la construcción de su relato.

De esa forma, Carri se desplaza de la ética del testimonio, que había caracterizado la época anterior, luchando contra ella y mostrando su inutilidad a la hora de reconstruir su biografía. La película muestra cómo muchos de los testigos no recuerdan o se niegan a dar su versión, mientras que los que acceden son descalificados por la directora, quien los expone en un televisor y los reduce a una ficción portadora de un discurso político demasiado idealista. ¿Poco real? Para Carri, si bien el pasado es inalcanzable y traumático, no se puede intentar acceder a él desde los testimonios, sino sólo desde el juego infantil, sin

1 Ésta comienza con el neorrealismo italiano y se consolida con el denominado movimiento de la Nouvelle Vogue en Francia. Si bien la discusión es amplia, podemos nombrar algunas características de esa escuela, como por ejemplo el estallido del relato, la problematización y ambigüedad en las categorías de espacio y tiempo, la puesta en problema de la referencialidad y la consolidación de un cine de lenguaje, que se contrapone a un cine espectacular. Todas características que están presentes en el filme de Carri y que ella recupera e interpreta para develar los mecanismos de construcción de relatos cinematográficos e incluso el propio. 
palabras y sin personas, con muñecos playmobil, pelucas y lugares de infancia (el campo de sus tíos en donde se crió luego de la desaparición de sus padres).

Durante toda la obra, la memoria de sus padres, y la propia, se devela como una construcción quebrada. Carri ya era consciente de aquello, y si bien trata de probarlo en el desarrollo del filme, la imposibilidad de un relato continuo, como la irrepresentabilidad e indecibilidad son premisas con las que ya había partido. Por ello es que se refugia en la experiencia estética, espacio donde puede jugar a construir su relato, donde puede reflexionar más libremente sobre su biografía y la de sus padres, o intentarlo sin resultados comprensibles. Ahí puede sentirse caprichosa sin el peso de los testimonios, defendiendo así una experiencia estética que, como advertía Adorno, se revela como un despliegue por intentar comprender el enigma, aunque éste sea intrínsecamente incomprensible.

Por último, y especialmente hacia el final, la obra se presenta como un relato sobre la forma en que su grupo generacional puede filmar una película y construir una narración personal acorde a su tiempo: desde una mirada subjetiva, pero haciendo visibles todas las imposibilidades y trabas de ser los herederos de un pasado traumático y pujando por un espacio en la industria cultural que los rechaza por no presentar un relato que sea nítido, pleno de sentido y continuo.

M

$M$ (2007), de Nicolás Prividera, es el resultado de un largo proceso de investigación para comprender los hechos que llevaron a la desaparición de su madre, Marta Sierra, en 1976. Dentro de ese proceso, Nicolás y su hermano han emprendido una causa penal, involucrando en la desaparición a Jorge Zorreguieta, padre de la princesa de Holanda y ministro de Agricultura del general Videla. La repercusión pública que provocó esta denuncia y el posterior encuentro con una antigua amiga de su madre desataron en el director la necesidad de investigar más para entender las causas de su desaparición y expresarlas en un documental.

Si nos detenemos en el título, puede sorprendernos que se recurra a una sola letra, la $\mathrm{M}$, pero detrás de esa aparente simplicidad se esconde un significante que puede llenarse con varios significados alusivos: $M$ de Marta (el nombre de su madre), $M$ de mamá, $M$ de Montoneros (la agrupación de la que ella habría sido miembro activo), $\mathrm{M}$ de militancia y militante, $\mathrm{M}$ de muerte, $\mathrm{M}$ de Memoria. Y si indagamos en la historia del cine, $M$ es también el nombre del primer filme sonoro de Fritz Lang, donde se narra la historia de un asesino psicópata al que las instituciones estatales no logran capturar, lo que mueve a los vecinos - en su mayoría vagabundos, prostitutas e incluso delincuentes- a organizarse para atraparlo y juzgarlo. A su vez, es importante acentuar que en gran parte de la película de Lang sólo conocemos al psicópata por un juego de sombras y de planos entrecortados, destacándose los claroscuros. Es sólo en el momento en que es atrapado y juzgado cuando se impone la claridad.

En ese sentido podemos pensar en el guiño cinéfilo de Prividera. Él también está cansado de las trabas e ineptitudes burocráticas del Estado y buscará dar claridad al caso de su madre por cuenta propia. También durante el filme se destacarán las sombras y los 
claroscuros, pero en este caso de los relatos que, a diferencia de lo que sucede en la obra de Lang, nunca se clarificarán del todo.

Si la película de Albertina Carri daba cuenta de la imposibilidad de la construcción de una realidad, $M$ se propone una reconstrucción en perspectiva, de la que es, sin embargo, consciente. Para ello Prividera exhibirá — en primera persona y con presencia plena ante las cámaras- su proceso de investigación, su juego casi detectivesco, al que accedemos por el gavilán que utiliza en todo el filme. Para indagar sobre el caso de su madre, el autor recurrirá a varios organismos institucionales de derechos humanos que puedan brindarle información, pero sólo encontrará trabas burocráticas. Seguirán los testimonios de personas cercanas a ella, los que dialogan entre sí, pugnando por dar su versión de los hechos. Desde allí los testigos acusan y se defienden, a la vez que nos muestran las complejidades y claroscuros de la militancia. Surgen así nuevos enigmas que no podrán ser resueltos.

De esa forma, en $M$ sí hay una voluntad de saber, que no se observaba en Los Rubios y que exhibe las oscuridades y complejidades de la «investigación» del autor. Para ello Prividera sí recurre a testimonios, pero sin omitir su propia opinión, y si bien se pone en el lugar del detective que investiga y «remueve las capas», también se hace cargo del lugar emotivo que el proceso implica: ser hijo de la desaparecida, cuyos últimos momentos está tratando de reconstruir. Ello se observa claramente cuando una compañera de su madre prefiere no hablar frente a la cámara, y él muestra su bronca alegando que no es asunto de «querer», manteniéndose al margen del orden de lo individual, sino que, como sucede con el imperativo moral de la memoria del Holocausto, prestar testimonio es una deuda social que se debe asumir.

Sin embargo, aunque Prividera no logra conocer con exactitud el grado de militancia de su madre ni su conciencia del peligro, $M$ nos ofrece discursos efectivos que instalan el debate y logran imponer un sentido, aunque también quebrado, abierto. Y lo hace con honestidad, volviendo visible el propio trabajo de construcción. Pero para él esto no significa sólo denunciar la construcción de la memoria como una quimera, sino exponer y exponerse: sus preguntas teóricas y personales, su bronca (como la que surge en un diálogo con su hermano), sus objetos seguros (fotografías y videos caseros familiares), sus trabas, hallazgos y logros.

Finalmente, a partir de sus conversaciones y acercamientos con los compañeros de trabajo de su madre, el autor y protagonista se decidirá y concretizará una placa conmemorativa a los detenidos desaparecidos del INTA (Instituto Nacional de Tecnología Agropecuaria), lugar donde ella trabajaba. De esa forma, para Prividera la memoria sí es importante, y si bien está trabada, burocratizada y oscurecida, hay que buscar la forma en que se haga visible. En ese caso, la conmemoración puede ayudar a resolver un duelo personal, ya que si la película no consigue relatar la historia de la madre, al menos la placa puede nombrar a los ausentes. Porque para ello no se pueden utilizar significantes vacíos, susceptibles de ser llenados con varios significados alegóricos, sino que es necesario instalar el nombre pleno, que no permite ambigüedades: Marta Sierra.

De esa forma, la cinta mira cada vez menos al pasado, centrándose en el presente y en el futuro. El director reclama un compromiso ético de la sociedad por la verdad y la justicia. Y si bien indaga en la historia de su madre y reclama por una necesidad personal - como un intento de duelo-, sabe que ese proceso implica a toda la comunidad. Sobre ello ya nos había advertido con la cita de Faulkner que abre el filme: «Su niñez estaba 
poblada de nombres, su propio cuerpo era como un salón vacío lleno de ecos sonoros de nombres derrotados. No era un ser, una persona. Era una comunidad». Y son esos múltiples nombres propios que suenan como ecos por distintas voces, con distintos matices, lo que Prividera quiere exhibir para hacer visible el complejo entramado social que hizo que su madre sea hoy una desaparecida.

\section{PAPÁ IVÁN}

En el mediometraje Papá Iván (2000), María Inés Roqué reconstruye la historia de su padre, Juan Julio Roqué, dirigente de las Fuerzas Armadas Revolucionarias (FAR) y miembro de la organización Montoneros, asesinado en 1977. Aquí la directora no intenta dar cuenta de los usos de la memoria o de su forma de construcción, como en los anteriores, sino que más bien realiza una indagación personal en la que convoca al fantasma del padre desde la intimidad del recuerdo. El resultado de esa evocación será el filme, en el que ensayará su forma de duelo.

De hecho, en Papá Iván la directora se presenta como voz en off (no en cuerpo presente como en $M$ o Los Rubios) indagando sobre su padre. El relato se configura a partir de entrevistas que realiza a sus compañeros de guerrilla, familiares, amigos, ex alumnas y a su esposa, Azucena Rodríguez. Este último testimonio es uno de los más destacados en el plano autobiográfico, ya que se presenta como una bisagra que exhibe las contradicciones de Iván como militante, padre y esposo. Azucena comenta que la separación de la pareja se produce cuando Roqué pasa a la clandestinidad, ya que ella no podía compartir la militancia de su marido, porque rechazaba la violencia como instrumento político; y también cuenta cómo se entera de otra pareja que Iván tuvo estando clandestino. Pero si hay algo que sobresale en cuanto a relevancia e impacto emotivo son las entrevistas que María Inés realiza a los ex montoneros que, según se rumorea, fueron traidores y entregaron a su padre.

De esa forma, el filme está compuesto casi en su totalidad por testimonios, situándose, a diferencia de los casos anteriores, dentro de la línea de los documentales testimoniales. Sin embargo, debemos destacar que la directora se aleja de la autocomplacencia, de las idealizaciones vacías, de las estampitas de héroe, a las que muchas obras de ese tipo recurren. María Inés nos presenta las contradicciones de Iván como padre, y desde allí las preguntas que la impulsan a filmar y que están presentes en todo el desarrollo de la cinta: ¿por qué mi papá hizo lo que hizo?, ¿por qué antepuso los valores de la revolución a los de sus hijos?, ¿por qué nos abandonó?

Ahora bien, la mirada intenta no juzgar y deja que los relatos dialoguen entre sí, exhibiendo las diversas argumentaciones. El resultado es el de un relato que oscila entre la figura de un padre que abandonó a sus hijos por la causa y la de un héroe revolucionario.

Para reconstruir la dimensión de Iván como militante recurre a diversos testimonios (incluido el de su madre), pero también incluye algunos recortes de prensa. En esa línea se destacan los que describen cómo su padre resistió hasta el final y murió combatiendo. Sobre su muerte se exhiben dos versiones: una es la de Miguel Bonasso, quien nos relata en clave épica que Roqué murió como un héroe, con una granada en la mano, luchando hasta el final; otra es la de quienes comentan que habría ingerido una pastilla de cianuro 
en el momento en que los militares llegan a su casa en la clandestinidad para atraparlo. Para reconstruir la figura de Iván como papá, María Inés Roqué recurre también a archivos personales, como cartas y fotografías.

Sin embargo, lo político público no puede ser separado de lo íntimo. Lo personal es político, y ambas esferas se entrelazan a lo largo de todo el filme. La directora lo sabe y no intenta separarlo, por ello nos va leyendo fuera de cámara, en fragmentos intercalados con los testimonios, la carta que su padre les deja. En ella Roqué les explica a sus hijos su posición política y el porqué de sus acciones, pero también usa un tono cariñoso y les remarca cuánto los quiere. Hacia el final, María Inés termina de leer la carta, que cierra con la siguiente expresión: «Libres o muertos, jamás esclavos». Esa frase resume la posición política que quiere transmitirles a sus hijos, pero es también la excusa que les brinda al abandonarlos por la causa. Excusa o justificación que María Inés trata de conciliar a la largo de la cinta, pero que como hija no consigue procesar, ya que, como ella misma menciona: "Hubiese preferido tener un padre vivo que un héroe muerto».

\section{A MODO DE CIERRE}

Luego del recorrido realizado por estos tres filmes podemos sacar algunas conclusiones. En primer lugar, sabemos que son tres documentales realizados por hijos de desaparecidos, y por lo tanto deben enfrentarse con la imposibilidad de llenar una ausencia primogénita. Se trata de cintas autobiográficas, donde ellos intentan evocar a sus padres desde un vacío material constitutivo, para reponer una memoria individual que se encuentra desde un inicio quebrada. Desde allí surgen las diferentes secuelas de un duelo irresuelto, que en cada caso se tratarán de modo distinto.

En Los Rubios se hará hincapié en la imposibilidad de la memoria, desmantelando sus procesos, exhibiéndolos, para finalmente descartarlos. Los testimonios y relatos sobre sus padres no le aportan nada a Albertina, porque nada le dicen sobre lo que ella es; son puros restos, que, como tales, no merecen ser tratados ni siquiera como ruina. Pero de todas formas decide jugar con ellos, y si los vecinos de la infancia los recordaban como «los rubios», ella jugará a ser «rubia». Recurriendo a pelucas, ella y sus compañeros de filmación descartarán cualquier aura sobre lo testimonial, ostentando que sus relatos ya no les sirven. Si sus padres fueron unos héroes ya no importa, porque no están, porque tuvo que criarse sin ellos. Ése es el gesto que prevalece en el documental, donde finalmente la memoria se deconstruye, y de aquella época sólo queda rescatar su imaginario íntimo e infantil como posibilidad lúdica: los juegos playmobil, la casa en el campo.

En $M$, si bien el director aparece en primera persona y asume el papel de investigador, su «yo» siempre se posiciona dentro de un «nosotros», dentro de una comunidad de la que es parte y a la que quiere interpelar. Su visión es menos individual que la de Carri, y aunque también desmantela los procesos de construcción de memoria y exhibe sus rabias, trabas y logros, no descartará el material que el proceso de investigación implica, porque para Prividera éste sí tiene un valor, un valor social. De esa forma, apelando a un nosotros, a una sociedad, denuncia y se pregunta por esas trabas, esas oscuridades que van surgiendo en el relato. El director retoma el imperativo moral de la memoria - que se había instaurado en el caso del Holocausto - para exigir justicia y verdad, pero también 
responsabilidad social. Por lo tanto, los restos que va encontrando en los testimonios no son desechables, sino que nos impulsan a mantener vivo el reclamo social. Si bien fracasa en muchas de sus búsquedas y se imponen los oscuros, en realidad no importa demasiado, siempre y cuando las sombras acechen a una sociedad que todavía tiene mucho que hacer por sus desaparecidos.

En el filme de Roqué hay una búsqueda mucho más personal que no trata de desmantelar los procesos de memoria o recuerdo, sino que a través de los testimonios, sobre todo de su madre y compañeros de militancia, intentará responder a la pregunta que como niña y hoy adulta sigue haciéndose: ¿por qué papá nos abandono? Para hacerlo, oscilará entre las dos figuras de Iván: el militante y el papá. Sin embargo, esos dos roles parecen no conciliarse, y los relatos testimoniales que María Inés expone darán cuenta de este desajuste.

Pese a sus diferencias, en los tres documentales que hemos revisado se observan distintas formas de afrontar el duelo irresuelto, aunque es en Los Rubios y $M$ donde se intentará una primera vía por las lógicas de las políticas institucionales en democracia. Sin embargo, ambos terminan por exponer las trabas burocráticas de las que ya sospechaban. De esa forma, si bien los directores exhiben los fantasmas que la ausencia de sus padres les produce, también lo hacen con los de toda la sociedad argentina. Y para ello desmantelan — para exhibir - los mecanismos de construcción de la memoria, tanto testimoniales como institucionales.

En los tres casos, además, se recurre a testimonios, pero son expuestos de forma que puedan dialogar, mostrando sus contradicciones y claroscuros, o en el caso más extremo, siendo reducidos a ficciones sin importancia (Los Rubios). Los testimonios son emotivos, pero no siempre complacientes, y así escapan a las visiones idealizadas, claras y santificadas de sus padres, revisando el pasado social y familiar desde una visión crítica, pero que no por ello está exenta de emotividad. En Papá Iván es donde más se confía en los testimonios, de tal forma que puede decirse que el documental prácticamente se articula en torno a ellos y utiliza otros recursos sólo de forma intercalada.

Otra semejanza es que los tres se alejan de las lógicas de la industria cultural, que propone imágenes limpias, sin oscuridades y con pleno sentido, renunciando a la posibilidad de un relato integral, a los discursos plausibles y sin fisuras. En M y Los Rubios se da cuenta de los complejos procesos de construcción de memoria desde un lenguaje cinematográfico que rompe con la idea de representación. Y en los tres casos, la perspectiva se aleja de los realismos que intentan autentificar lo real desde una estética que repite eslóganes vacíos.

A su vez, es importante destacar que ninguno de los directores hace referencia al horror vivido por sus padres de forma directa. No existe en estos documentales un interés por mostrar imágenes de horror, ni por exponer relatos de tortura, enfoque que había caracterizado a los filmes de ficción y documentales de los primeros años de la democracia ${ }^{2}$. De esa forma, tanto Los Rubios, como M y Papá Iván se desentienden de la discusión que había girado en torno a la exhibición del horror, sus posibilidades de representación y

2 Enfoque que es producto de una época en la que se produjeron una serie de procesos que significaron una fuerte visibilización de testimonios directos de los sobrevivientes, en los que relataban con detalle la tortura, violencia y desaparición. Nos referimos a los primeros años de retorno a la democracia, cuando se produce la transmisión del Juicio a las Juntas y el libro informe Nunca Más, ambos fenómenos masivos que permitieron que la sociedad pudiera escuchar los testimonios que se presentaban como un catálogo de horrores. 
sus límites éticos, para situarse en otra problemática más subterránea y menos explícita: la de los síntomas que la violencia, la falta y la injusticia producen en los hijos y en toda una sociedad.

Finalmente, el legado social que los tres documentales nos ofrecen es una reflexión sobre los procesos de memoria que replantea el lugar del testimonio, a la vez que nos brinda un relato donde la consolación es reemplazada por una conmoción activa que interpela a toda la sociedad. El legado individual, por otra parte, es para sus directores el intentar una catarsis individual desde la experiencia estética - en este caso desde un registro audiovisual—, y a partir de ese intento reconocer que más allá de las imposibilidades y las discontinuidades existe un espacio donde se pueden encontrar ciertas ruinas efectivas: lo íntimo y familiar, los objetos y espacios de la infancia (Los Rubios), las fotografías y videos familiares (M y Papá Iván) y las cartas (Papá Iván). Así, si hay posibilidad de conocer será a través de residuos o grietas de la memoria: imágenes, objetos, textos.

\section{REFERENCIAS}

Adorno, Theodor. Teoría Estética. Barcelona: Orbis, 1984. Medio impreso.

Benjamin, Walter. La Dialéctica en Suspenso. Fragmentos sobre la Historia. Santiago: ARCIS-Lom, 1999. Medio impreso.

Benveniste, Emile. Problemas de Lingüística General. México D.F: Siglo XXI, 1974. Medio impreso.

Didi-Huberman, Georges. Imágenes pese a todo. Memoria visual del Holocausto. Barcelona: Paidós, 2004. Medio impreso.

Simmel, George. "El concepto y la tragedia de la cultura». Sobre la aventura. Barcelona: Península, 2002. Medio impreso.

Recepción: 21 de octubre de 2010

Aceptación: 20 de diciembre de 2010 